\title{
К ВОПРОСУ О ПРОБЛЕМЕ КВАЛИФИКАЦИИ ВНЕДОГОВОРНЫХ ТРАНСГРАНИЧНЫХ ОБЯЗАТЕЛЬСТВ (НА ПРИМЕРЕ РОССИЙСКОЙ ФЕДЕРАЦИИ И ИСПАНИИ)
}

\begin{abstract}
Аннотация: Вопрос проблемы квалификации в международном частном праве является одним из фундаментальных. В доктрине международного частного права отмечается, что квалификация осложнена в связи с особенностями самого международного частного права. В свою очередь, сложность квалификации внедоговорных трансграничных обязательств автором рассматривается в связи с отсутствием легитимного определения внедоговорных обязательств, неоднородным характером данного вида обязательств, а также появлением новых видов. В ХХІ в. Российской Федерации и Испании правовая квалификация внедоговорных трансграничных обязательств эволючионировала. Так, в Испании предусмотрена автономная квалификация внедоговорных трансграничных обязательств. В Российской Федерации общие правила квалификации по lex fori не изменились. Однако исходя из Проекта изменений Гражданского кодекса Российской Федерации некоторые виды внедоговорных трансграничных обязательств (обязательства, возникающие вследствие причинения вреда, обязательства, возникающие вследствие недобросовестного ведения переговоров о заключении договора и неосновательное обогащение), в случае наличия тесной связи, возможно, квалифицировать в качестве договорного обязательства.

На эволюичию проблемы квалификации внедоговорных трансграничных обязательств в Российской Федерации оказали влияние следующие тенденции, а именно: совершенствования российского законодательства (в частности, интересующий нас раздел VI «Международное частное право» Гражданского Кодекса РФ), а также тендениия кгармонизации российских коллизионных норм с коллизионными нормами Европейского Союза. В Испании эволюции данного вопроса послужила унификаиия внедоговорных трансграничных обязательств в рамках ЕС, в Регламенте «Рим II» 2007 г.

Ключевые слова: Юриспрудениия, квалификация, толкование, эволюиия, понятие, обязательства, право, гармонизацчия, законодательство, тенденциии
\end{abstract}

и нтерес к вопросу правовой квалификации попрежнему актуален, как в международном частном праве, так и в теории государства и права ${ }^{1}$. Однако, как в международном частном праве Российской Федерации (далее - РФ), так и в международном частном праве Испании нет отдельного исследования, посвященного вопросу правовой квалификации внедоговорных трансграничных обязательств ${ }^{2}$.

\footnotetext{
${ }^{1}$ В международном частном праве проблема квалификации рассматривается также в двух диссертационных исследованиях. См.: Бирюкова Н.С. Проблема квалификации в международном частном праве. Дисс. к. ю. н. М., 2007; Абраменков М.С. Проблемы коллизионно-правового регулирования наследственных отношений в международном частном праве. Дисс. к. ю. н. М., 2007.

Вопрос правовой квалификации и толкования также исследуется в диссертационных исследованиях в рамках теории государства и права. См.: Болонин С.Ю. Правотолкование и правовое регулирование. Дисс. к. ю. н. Казань, 2010; Коробов А.П. Правовая квалификация: основы, понятие, значение, этапы. Дисс. к. ю. н. Саратов, 2005. Надежин Г.Н. Доктринальное толкование норм права. Дисс. к. ю. н. Нижний Новгород, 2005; Новиков Н.И. Нормативное толкование в механизме правового регулирования. Дисс. к. ю. н. Ростов-на-Дону, 2009.

${ }^{2}$ Однако, проблема квалификации категории «место совершения деликта» («lex loci delicti commissi), а также значение квалифи-
}

В настоящее время доктриной международного частного права понятие «правовая квалификация» определяется как «установление содержания правовых понятий, образующих коллизионную норму или толкование юридических категорий применимой правовой системы» ${ }^{3}$. Проблема квалификации состоит в том, что фактическим обстоятельствам, к которым необходимо применить коллизионную норму, следует дать правовое толкование, которое зависит от содержания еще не выбранного применимого права ${ }^{4}$. Так, от решения проблемы квалификации зависит не только выбор коллизионной нормы, относящейся к определенной области обще-

кации для статута деликтного обязательства были рассмотрены в рамках диссертации Звекова В.П. Обязательства из причинения вреда здоровью в международном частном праве. Дис. к.ю.н. М., 1964, а также в рамках итогового исследования Звекова В.П. Коллизии законов в международном частном праве. М., 2007. С. 297-326. В Испании проблема квалификации внедоговорных трансграничных обязательств затронута в статье Rafael Arenas García «La distinctíon entre obligaciones contractuales y obligaciones extracontractuales en los instrumentos comunitarios de derecho internacional privado». Anuario de derecho internacional privado, 2006. № 4.

${ }_{3}^{3}$ Федосеева Г.Ю. Международное частное право. М., 2007. С. 120.

${ }^{4}$ Федоссева Г.Ю. Указ. соч. С. 124. 
ственных отношений, но, также и выбор между такими коллизионными нормами, которые принадлежат к одной и той, же области правового регулирования 5 .

Для того чтобы применить коллизионную норму и выбрать применимое право, необходимо ее истолковать, что означает, во-первых, раскрыть содержание юридических понятий; во-вторых, соотнести их с фактическими обстоятельствами, при которых эта норма должна быть применена, с тем, чтобы убедиться, что фактические обстоятельства соответствуют объему и привязке коллизионной нормы ${ }^{6}$. При этом толкование или юридическая квалификация коллизионных норм серьезно отличается от толкования других правовых норм$^{7}$. Особенности порождаются тем, что фактические обстоятельства, при которых коллизионная норма должна быть применена, связаны с разными государствами и, соответственно, находятся в правовом поле разных государств ${ }^{8}$. Право разных государств по-разному регулирует одинаковые отношения, а значит, придает одним и тем же фактическим обстоятельствам разную правовую окраску, дает разную юридическую квалификацию9 . Соответственно, квалификация в международном частном праве является более сложной. Таким образом, сложность правовой квалификации связана с особенностями международного частного права, а именно с наличием иностранного элемента, т.е. трансграничностью регулируемых отношений.

Квалификация внедоговорных трансграничных обязательств, также осложнена спецификой соответствующих отношений (внедоговорным характером), их многообразием и разноплановостью.

До настоящего времени ни в национальном праве, ни в международных актах не сложилось единое легитимное определение внедоговорных обязательств. В доктрине российского права имеются расхождения по поводу выделения сущностных характеристик или признаков данного вида обязательств, что в значительной степени осложняет процесс квалификации.

В.Л. Толстых полагает, что объективно процесс квалификации в международном частном праве со-

\footnotetext{
${ }^{5}$ Абраменков М.С. Проблемы коллизионно-правового регулирования наследственных отношений в международном частном праве. Дисс. к. ю. н. М., 2007. С. 142.

${ }^{6}$ Международное частное право. Отв. ред. Дмитриева Г.К. 3-е изд., перераб. и доп. М., 2010. С. 139.

${ }^{7}$ Необходимо отметить, что квалификация внедоговорных трансграничных обязательств в Испании отличается от квалификации других коллизионных норм. Применительно к внедоговорным трансграничным обязательствам осуществляется автономная квалификация.

${ }^{8}$ Указ. соч. Отв. ред. Дмитриева Г.К. С. 139.

${ }^{9}$ Указ. соч. Отв. ред. Дмитриева Г.К. С. 140.
}

стоит из трех стадий: 1) толкование нормы; 2) анализ отношения; 3) сравнение нормы и отношения. Применение нормы»10. В результате последовательной реализации всех трех стадий возможно корректное применение нормы.

Наиболее распространенным способом решения проблемы квалификации является применение lex fori, что означает, необходимость толкования коллизионной нормы, в том числе содержащую отсылку к «lex loci delicti commissi» в соответствии с отечественными представлениями и концепциями, известными суду.

Проблемы квалификации, возникающие при поиске применимого права к внедоговорным трансграничным отношениям, возникают в связи с тем, что термин «внедоговорные обязательства», используемый как в законодательстве РФ, Испании, так и других государств имеет разное содержание. В этой связи при возникновении необходимости в квалификации суд в первую очередь должен определить, являются ли соответствующие обязательства внедоговорными, а затем уже имеют ли они трансграничный характер, что повлечет применение норм международного частного права.

Полагаем, что также может возникнуть другой вопрос так называемой «первичной квалификации», например, толкование коллизионной привязки lex loci delicti commissi. (как место причинения вреда или место наступления последствий).

Проблема правовой квалификации внедоговорных трансграничных обязательств во многом обусловлена сложностями в определении сущности и видов внедоговорных трансграничных обязательств. Полагаем, что выстраивается связь между следующими процессами: расширение круга внедоговорных трансграничных обязательств приводит к усложнению коллизионных привязок (к закреплению гибких привязок ${ }^{11}$; субсидиарных; к увеличению альтернативных привязок), что, в конечном итоге, приводит к усложнению квалификации внедоговорных трансграничных обязательств.

М.С. Абраменков полагает, что, назвав ст. 1187 ГК РФ «Квалификация юридических понятий при определении права, подлежащего применению», законодатель volens nolens указал, что толкование юридических понятий и юридическая квалификация в международном частном праве, (как таковая) идентичны. В результате остается не-

\footnotetext{
${ }^{10}$ Tолстых В.Л. Международное частное право: коллизионное регулирование. СПб, 2004. С. 173.

${ }^{11}$ Нельзя не согласиться с мнением Бирюковой Н.С., что принцип наиболее тесной связи, с присущей ему смысловой широтой, не решает проблему квалификации, а лишь переводит ее на иной уровень. Следовательно, можно предположить, что современная тенденция к закреплению гибких коллизионных норм приводит к осложнению вопроса правовой квалификации в международном частном праве.
} 


\section{Право и политика $4(160) \cdot 2013$}

ясным, о каких именно юридических понятиях в данном случае идет речь» ${ }^{12}$.

Действительно, в ст. 1187 ГК РФ используются оба термина, как квалификация, так и толкование. В свою очередь Н.С. Бирюкова считает, что основное отличие правовой квалификации от толкования заключается в том, что квалификация - это не просто уяснение содержания, это еще и оценка. При этом оценка не только собственно нормы права, но и фактической ситуации. Особенностью правовой квалификации как оценки следует считать то, что она фиксирует наличие (или отсутствие) у фактических обстоятельств конкретной жизненной ситуации, признаков юридических фактов ${ }^{13}$. В качестве сущностной характеристики правовой квалификации А.П. Коробов ${ }^{14}$ выделяет оценку деяний и событий с точки зрения их роли в возникновении правоотношений. Автор полагает, что понятие «правовая оценка» является более широким, чем понятие «правовая квалификация» ${ }^{15}$.

Представляется возможным согласиться с позицией А.П. Коробова и Н.С. Бирюковой, заключающейся в рассмотрении правовой квалификации через призму правовой оценки.

Исходя из широкого понимания правовой квалификации суд, рассматривая конкретное дело оценивает: во-первых, насколько конкретное обязательство обладает признаками, позволяющими говорить о внедоговорном характере данного обязательства, т.е. суд сопоставляет признаки конкретного обязательства из конкретного дела с признаками, характерными для внедоговорных обязательств в целом. К тому же оценивает, достаточно ли наличия того или иного признака для квалификации обязательства в качестве внедоговорного;

во-вторых, присущ ли отношению иностранный элемент, характер трансграничности, выходит ли отношение за рамки национального гражданского права и подпадает ли под предмет правового регулирования международного частного права.

Необходимо отметить, что в некоторых случаях суд также будет оценивать насколько конкретное обязательство имеет «тесную» связь с договором, для того чтобы квалифицировать его в качестве договорного обязательства. Например: п. 3 ст. 1219; ст. 1220.1; ст. 1222.1; п. 2 ст.1223 в Проекте изменений в ГК РФ. Безусловно, в данном случае имеет место новая тенденция в квалификации внедоговорных трансграничных обязательств, а именно возможность квалификации вида

\footnotetext{
12 Абраменков М.С. Проблемы коллизионо-правового регулирования наследственных отношений в международном частном праве. Дисс. к. ю. н. М., 2007. С. 145.

${ }^{13}$ Бирюкова Н.С. «Проблема квалификации в международном частном праве». Дисс. к. ю. н. М., 2007. С. 80.

${ }^{14}$ Коробов А.П. Правовая квалификация: основы, понятие, значение, этапы. Автор. дисс. к. ю. н. Саратов, 2005. С. 13.

15 Там же. С. 13.
}

внедоговорного трансграничного обязательства в качестве договорного ${ }^{16}$. Так, в Комментарии к Проекту изменений ГК РФ, в п. 3 ст. 1219 указано, что такой подход отличается от общепринятого понимания обязательства вследствие причинения вреда как строго внедоговорного обязательства ${ }^{17}$.

В ГК РСФСР 1964г. ${ }^{18}$, а также в Основах гражданского законодательства Союза ССР и республик 1991г ${ }^{19}$. не было даже упоминания о правовой квалификации. В действующем ГК РФ в ст. 1187 закреплен механизм квалификации юридических понятий при определении права, подлежащего применению. В Проекте изменений в Гражданский Кодекс РФ $\Phi^{20}$ (далее - Проект ГК РФ) положения данной статьи оставлены в прежнем виде.

В Испании, как и в РФ, толкование юридических понятий осуществляется в соответствии со своим правом ${ }^{21}$. Вопрос квалификации тех юридических институтов (понятий), которые не известны испанскому праву, в ГК Испании не решен.

В этой связи в 2011 г. испанские ученые Карло Эсплигес Мота (Carlos Espligues Mota) и Хосе Луис Иглесиас Буигес (José Luis Iglesias Buhigues) предложили два возможных решения:

«1. Законодатель моделирует правовое основание коллизионной нормы таким образом, что иностранная норма будет применена к институтам, которые могут быть не известны испанскому праву. Исключение из данного правила составляют те институты, которые противоречат публичному порядку» 22 .

2. В тех случаях, когда законодатель молчит, правоприменительный орган будет тем исполнителем, который противостоит конкретной ситуации, принуждая себя к максимальному пониманию юридических понятий, с целью «подгонки» к реалиям неизвестного для испанского права института» ${ }^{23}$.

\footnotetext{
${ }^{16}$ Речь идет о двух видах обязательств, которые всегда рассматривались в качестве внедоговорных: обязательств, возникших вследствие причинения вреда и неосновательное обогащение, а также нового вида внедоговорного обязательства - обязательство, возникшее вследствие недобросовестного ведения переговоров о заключении договора.

${ }^{17}$ Комментарий к Проекту изменений Гражданского кодекса Российской Федерации. Обзор подготовлен специалистами АО «Консультант Плюс».

18 «Свод законов РСФСР», т. 2, с. 7.

${ }^{19}$ «Ведомости СНД и ВС СССР», 26.06.1991, N 26, ст. 733.

${ }^{20}$ Документ опубликован не был. См.: СПС «Консультант Плюс».

${ }^{21}$ П. 1 ст.12 ГК Испании закрепляет: «Квалификация в целях определения применимой коллизионной нормы всегда производится согласно испанскому закону».

${ }^{22}$ Derecho internacional privado. 5a edición. Carlos Espligues Mota, José Luis Iglesias Buhigues. Valencia, 2011. P. 222.

${ }^{23}$ См.: Там же. Р. 222.
} 
Полагаем, что в данном случае суд Испании будет стремиться применить свое право.

Интересно, что в п. 2 ст.1187 ГК РФ также предусмотрена возможность применения иностранного права. Однако российский законодатель не указывает, какое иностранное право является применимым. Г.К. Дмитриева отмечает, что в таком случае возможны два варианта: применение права, с которым отношение наиболее тесно связано (Proper Law), или права, которое регулирует отношение в целом (lex causae) ${ }^{24}$. Соответственно, вопрос квалификации понятия, которое не известно внутреннему праву, является настолько сложным, что на законодательном уровне он исчерпывающим образом не урегулирован в обоих государствах.

Правовая квалификация и правовая оценка, в значительной степени сопряжены с эволюционными процессами в праве. В сфере внедоговорных трансграничных отношений в настоящее время отчетливо наметились тенденции, способные, в определенном смысле осложнить осуществление правовой квалификации.

Во-первых, наблюдается «сближение» договорных и внедоговорных обязательств, для целей поиска применимого права. В частности, указанная тенденция коснулась следующих видов внедоговорных трансграничных обязательств: обязательств, возникающих вследствие причинения вреда (п. 3 ст. 1219 Проекта изменений в ГК РФ $)^{25}$, обязательств, возникающих вследствие недобросовестного ведения переговоров о заключении договора (ст. 1222.1 Проекта изменений в ГК РФ), неосновательного обогащения (ст. 1223 Проекта изменений в ГК РФ) ${ }^{26}$.

Во-вторых, неоднородность внедоговорных трансграничных обязательств, появление новых видов, их множественность, безусловно влияют на квалификацию.

Полагаем, что выстраивается связь между следующими процессами: расширение круга внедоговорных трансграничных обязательств приводит к усложнению коллизионных привязок (к закреплению гибких привязок ${ }^{27}$;

${ }^{24}$ Международное частное право. Отв. Ред. Дмитриева Г.К. 3-е изд., перераб. и доп. М., 2010. С. 144.

${ }^{25}$ Необходимо отметить, что в комментарии к Проекту изменений ГК РФ отмечается, что подход, продемонстрированный в данной статье, отличается от общепринятого понимания обязательства вследствие причинения вреда как строго внедоговорного обязательства.

${ }^{26}$ Интерес представляет также ст. 1220.1 Проекта изменений в ГК РФ, посвященная возмещению вреда страховщиком. В ней указано: «Требование о возмещении вреда может быть предъявлено потерпевшим непосредственно страховщику, если это допускается по праву, подлежащему применению к обязательству вследствие причинения вреда, либо по праву, подлежащему применению к договору страхования».

${ }^{27}$ Нельзя не согласиться с мнением Бирюковой Н.С., что принцип наиболее тесной связи, с присущей ему смысловой широтой, не субсидиарных; к увеличению альтернативных привязок), что, в конечном итоге, приводит к усложнению квалификации внедоговорных трансграничных обязательств.

В-третьих, наметилась устойчивая тенденция расширения сферы применения - принципа автономии воли сторон, в том числе в отношении обязательств вследствие причинения вреда и неосновательного обогащения Проект ГК РФ. (Ст. 1223.1). В действующем ГК РФ предусматривается возможность выбора только права страны суда, а в Проекте ГК РФ возможен выбор любого правопорядка, ограниченный, однако, действием императивных норм страны, с которой соответствующее обязательство реально связано ${ }^{28}$. Необходимо отметь, что во второй части ст. 1222.1 Проект ГК РФ указано: «Если применимое право не может быть определено в соответствии с частью первой настоящей статьи, право, подлежащее применению, определяется в соответствии со статьями 1219 и 1223.1 настоящего Кодекса». Соответственно, сложность квалификации в данном случае заключается в том, что исходя из части второй ст. 1222.1 Проект ГК РФ возможен случай квалификации по праву, выбранному сторонами, а выбранный правопорядок, как отмечали выше, может быть любым 29.

Доктрина международного частного права обладает тремя возможными способами решения «конфликта квалификации» ${ }^{30}$. Первый способ - квалификация по закону страны суда - (lex fori), т.е. суд осуществляет квалификацию в соответствии со своим внутренним правом. Так, аргументом в пользу использования lex fori служит тот факт, что коллизионная норма является нормой внутреннего права, и поэтому пользуется понятиями своей правовой системы ${ }^{31}$. В соответствии с п.1 ст. 1187 ГК РФ и п. 1 ст. 12 ГК Испании квалификация должна осуществляться по lex fori.

В испанской доктрине XXI в. нет единства. Так, Фернандес Pocac (Fernandes Rosas) и С. Санчес Лоренсо

решает проблему квалификации, а лишь переводит ее на иной уровень. Следовательно, можно предположить, что современная тенденция к закреплению гибких коллизионных норм приводит к осложнению вопроса правовой квалификации в международном частном праве.

${ }^{28}$ Необходимо отметить, что данное ограничение автономии воли имеет место также и в договорных обязательствах в п. 5 ст. 1210 ГК РФ.

${ }^{29}$ Поскольку несмотря на то, что в соответствии с общим правилом квалификация осуществляется по lex fori, в п. 2 ст.1187 ГК РФ законодателем предусмотрены обстоятельства, при которых возможна квалификация по иностранному праву.

${ }^{30}$ Применительно к рассматриваемой статье конфликт квалификации имеет место, когда термин «внедоговорные обязательства» используется государствами (напр., РФ и Испанией), но само понятие данного термина может не совпадать.

${ }^{31}$ См.: Международное частное право. Отв. Ред. Дмитриева Г.К. 3-е изд., перераб. и доп. М., 2010. С. 141. 


\section{Право и политика $4(160) \cdot 2013$}

(S. Sanchez Lorenzo) выступают за применение lex fori, поскольку, если речь идет о квалификации для применения внутреннего международного частного права, то квалификация lex fori является общепринятой. В свою очередь, А. Аудит (A. Audit) полагает, что квалификация по lex fori не может быть принята в случае, если будет происходить применение тех же самых механизмов в иной форме, чем в той, которая была использована судьей, рассматривающим дело ${ }^{32}$.

Второй способ разрешения конфликта квалификации - квалификация по lex causae, т.e. по праву, регулирующему существо отношения. Е.В. Кабатова отмечает, что воплотить в жизнь принцип lex causae мешает одно препятствие: «оценить правоотношение, а также подобрать подходящую коллизионную норму, устанавливая ее смысл, сферу действия и т.д. приходится в условиях, когда lex causae еще не установлен, в лучшем случае, о нем можно лишь догадываться. Квалифицировать приходится тогда, когда иного права, кроме собственного, в распоряжении суда не имеется» ${ }^{33}$. Полагаем, что данный аргумент Е.В. Кабатовой является весомым и правильным. Действительно, на начальном этапе правоприменительный орган имеет дело со своим национальным правом. О неуместности применения lex causae пишет С. Бариатти (S. Bariatti). Его позиция основывается на том, что коллизионные нормы ЕС имеют универсальный характер, а данная квалификация может привести к отсылке к праву третьего государства ${ }^{34}$.

Квалификация по lex causae не получила доктринальной поддержки, хотя и нет безнадежных препятствий к ее применению. Так, С. Алварес Гонсалес (S. Alvarez Gonsalez) полагает, что нет логической несовместимости в использовании lex causae, поскольку исчезает другая проблема, а именно - конфликт квалификации.

В защиту квалификации по lex causae Рафаель Аренас Гарсиа (Rafael Arenas García) обращает внимание на то, что сложности не будут иметь места, если отличать толкование от квалификации. Так, толкование должно происходить в автономном порядке, поскольку правоприменительные органы обращаются в область ЕС и руководствуются общими понятиями, используемыми в государствах-членах EC. В случае, если нет проблем в применении права того государства, которое не является членом ЕC, то и нет

\footnotetext{
${ }^{32}$ Cм.: Rafael Arenas García. La distinction entre obligaciones contractuales y obligaciones extracontractuales en los instrumentos comunitarios de derecho internacional privado. Anuario de derecho internacional privado, 2006. № 4. P. 400. (http://adipr.files.wordpress. com/2007/06/aedipr-2006-jornadas-arenas-garcia.pdf). Дата посещения 5.01.13.

${ }_{33}$ Международное частное право. Т.1. Общая часть. Отв. ред. Лебедев С.Н., Кабатова Е.В. М., 2011. С.267.

${ }^{34}$ Rafael Arenas García. Указ. соч. Р. 415.
}

причин для препятствий вступления права третьего государства в фазу квалификации ${ }^{35}$. Полагаем, что в данном случае Rafael Arenas García (Рафаэль Аренас Гарсиа) имеет в виду, что если обе стороны из государств-членов ЕС, то следует толковать в соответствии с общими понятиями $\mathrm{EC}$, т.е. используя метод сравнительного-правоведения. Если же одна из сторон не из государства-члена ЕС, то здесь речь может идти о квалификации по lex causae.

Третий способ - «автономная квалификация»: для того, чтобы выполнить роль связующего звена между правом разных государств, коллизионная норма должна пользоваться некими общими для права разных государств понятиями, которые выводятся путем сравнительного изучения и обобщения, однородных цивилистических понятий права разных государств ${ }^{36}$. В российской доктрине противником данной концепции выступает В.А. Канашевский, который полагает, что предложение об автономной квалификации хотя и выглядит привлекательным, но практически мало осуществимо, поскольку нельзя требовать от суда знания и применения метода сравнительного правоведения ${ }^{37}$.

Способ автономной квалификации, как удобный для применения, декларируется в «Рим II». Так, в п. 11 «Рим II» закреплено: «Понятие внедоговорного обязательства является неодинаковым в разных государствах-членах. Поэтому в целях настоящего Регламента оно должно рассматриваться как автономное понятие».

Соответственно, п. 1 ГК Испании закрепляет lex fori, a п. 11 «Рим ІІ» устанавливает автономную квалификацию. Поскольку нормы «Рим II» преобладают над нормами ГК Испании, то квалификация осуществляется по автономному критерию.

Таким образом, в международном частном праве Испании, прослеживается тенденция отхода от способа квалификации по lex fori в пользу автономной квалификации.

Использование автономной квалификации способствует созданию единого международного частного права европейских государств. К данной тенденции ведут следующие факты: принятие конвенций, унифицирующих коллизионные и материальные нормы в рамках ЕC; возложение на суда обязанности обобщения тех правовых понятий, которыми пользуются государства-члены ЕС.

Действительно, отмеченные три способа преодоления конфликта квалификации остаются актуальными и в современных условиях эволюционирования международного частного права и его инструментария в РФ и Испании.

\footnotetext{
${ }^{35}$ Rafael Arenas García. Указ. соч. Р. 416.

${ }^{36}$ Международное частное право. Отв. Ред. Дмитриева Г.К. 3-е изд., перераб. и доп. М., 2010. С. 142.

${ }^{37}$ Канашевский В.А. Международное частное право. М., 2009. C. 114 .
} 
Альфонсо-Луис Кальво Карравака (Alfonso-Luis Calvo Carravaca), Javier Хавиер Караскоса Гонсалес (Carrascosa González) обратили внимание на международные договоры, которые способствуют единообразному регулированию ${ }^{38}$ : В первую очередь, авторы, отмечают, что определения, которые указаны в международных договорах, будут толковаться одинаково вне зависимости от места рассмотрения спора. Так, в качестве примера приводится п. 2 ст. 1 Гаагской конвенции «О праве, применимом к дорожно-транспортным происшествиям» 1971 г., в котором раскрывается определение «дорожно - транспортного происшествия». Соответственно, правоприменительные органы руководствуются теми понятиями, которые предусмотрены международными механизмами. Например, Европейский суд использует те понятия, которые указаны Римской конвенцией 80 г. «О праве применимом, к договорным обязательствам». Так, суд будет пользоваться теми терминами и определениями, которые указаны в конвенции. Так же обстоит дело и с внедоговорными обязательствами, примером служит: «Рим II».

В нормах международных договоров могут присутствовать коллизионные нормы, указывающие на то, на основе какого правопорядка должны уточняться понятия. Примером служит, в ст. 12 Гаагской конвенции «О компетенции и применимом праве в отношении защиты несовершеннолетних» 1961 г. положение, что несовершеннолетним признается лицо, которое признано таковым по закону гражданства или места жительства.

В конвенции может содержаться отсылка к международному частному праву какого-либо государства. Авторы в качестве примера приводят п. 2 ст. 22 Регламента Совета ЕС 44/2001 от 22.12.2000 г. «О юрисдикции, признании и принудительном исполнении судебных решений по гражданским и торговым делам», что для определения «местонахождения компании» суд должен применять нормы международного частного права.

В конвенции также возможно отнесение вопроса к определенному институту применимого права. Например, ст. 15 «Рим II» определяет сферу действия права, подлежащего применению; п. «б» ст. 15 «Рим ІІ» ограничение ответственности определяется как вопрос, относящийся к внедоговорной ответственности, а не к процессуальному статуту. Соответствующая квалификация приведет к тому, что применимым правом будет, как указано в данной статье, «право, подлежащее применению к внедоговорному обязательству согласно настоящему Регламенту»з9.

${ }^{38} \mathrm{Cm}$ : Derecho internacional privado. Alfonso-Luis Calvo Carravaca, Javier Carrascosa González. Granada, 2008. Volume 1. P. 270-271.

${ }^{39}$ (http://eulaw.edu.ru/documents/legislation/collision/vnedogovornoe.htm). Дата посещения 5.01.13.
В данном случае, уместно говорить о «процессуальной» квалификации ${ }^{40}$, поскольку основная суть проблемы «процессуальной» квалификации связана с необходимостью определить, относится ли тот или иной институт гражданского процесса, к категории материальных норм или к категории норм процесса, а также в соответствии с какими правилами (правом какого государства) это необходимо определять ${ }^{41}$.

Бирюкова Н.С. описывает данное явление как переплетение вопроса «процессуальной» квалификации с правовой квалификацией, связанной с определением применимого права ${ }^{42}$. С одной стороны, данное явление упрощает задачу суда; с другой стороны, демонстрирует сложность правовой квалификации, поскольку здесь нужно также разграничить, к нормам материального или процессуального права относится тот или иной институт права, что относится к особенностям права разных государств.

Интерес в этой связи представляет ст. 8 Гаагской конвенции «О праве применимом, к дорожно-транспортным происшествиям» 1971 г., по которой исковая давность относится к вопросу «внедоговорной ответственности», а не к вопросу «процессуальному» ${ }^{43}$. Следовательно, отнесение вопроса к определенному институту в самой конвенции приводит к снятию проблемы квалификации в странах, подписавших соответствующую конвенцию.

Вышеназванные конвенции служат доказательством эволюции правовой квалификации внедоговорных трансграничных обязательств: присутствует автономная квалификация (отход от lex fori); происходит расширение правовой квалификации, а именно рассмотрение в ее рамках вопросов «процессуальной» квалификации ${ }^{44}$.

В судебном решении Габриель (Gabriel) ${ }^{45}$ от 11. 06.2002 г. перед судом стоял вопрос, является ли договорным обязательством выполнение ходатайства работодателем о предоставлении выигранной премии. Европейский суд квалифицировал права работника в качестве прав, связанных с контрактом, заключенным между сторонами. Таким образом, Европейским судом был применен договорный режим к обязательствам, отраженным в исковом требовании, несмотря на то, что он не квалифицировал

\footnotetext{
${ }^{40}$ Термин используется Бирюковой Н.С. Указ. соч. С. 62.

${ }^{41}$ См.: Бирюкова Н.С. Указ. соч. С. 62.

${ }^{42}$ См.: Бирюкова Н.С. Указ. соч. С. 63.

${ }^{43}$ См.: Указ. соч. Alfonso-Luis Calvo Carravaca, Javier Carrascosa González. P. 271.

${ }^{44}$ Данный термин используется в том же значении, что у Бирюковой Н.С. Там же. С. 62.

${ }^{45}$ См.: Rafael Arenas García. Указ. соч. Р. 403.

(http://adipr.files.wordpress.com/2007/06/aedipr-2006-jornadasarenas-garcia.pdf). Дата посещения 5.01.13.
} 


\section{Право и политика $4(160) \cdot 2013$}

данные обязательства в качестве договорных. Можно предположить, что Европейский суд исходит из того, что сам факт наличия договора между сторонами, позволяет квалифицировать обязательство в качестве договорного. Рафаель Аренас Гарсиа (Rafael Arenas García) в своей рабо$\mathrm{Te}^{46}$ отмечает, что также из современного законодательства Испании вытекает, что можно исходить из признака наличия соглашения и квалифицировать обязательство как договорное. Так, в случае отсутствия соглашения между сторонами речь идет о внедоговорных обязательствах, что не дает возможности обращения к «Рим I». Рафаель Аренас Гарсиа (Rafael Arenas García) полагает, что данное положение стоит на строгой интерпретации принципа «относительности договора», тем же самым ограничивая или устраняя возможность использования договорной юрисдикции в отношении тех лиц, которые не являлись первоначальными сторонами по договору. По мнению автора, принцип «относительности договоров» чужд частному праву европейских государств, в которых признают действительность договора перед теми лицами, которые не являлись первоначальными сторонами по договору. Отрицание возможности существования договорной связи между сторонами, которые не являлись первоначальными сторонами, автором расценивается как возврат в ранний период развития частного права. Автор справедливо отмечает, что договор является ключевым элементом в соединении экономических отношений, а также, что его связь идет дальше тех людей, которые заключили договор ${ }^{47}$.

Интересен вывод Рафаэля Аренас Гарсиа (Rafael Arenas García) по проблеме квалификации: в случае, если в одном деле - одно и то же обязательство по «Рим I» будет рассматриваться как договорное, а по «Рим II»- как внедоговорное, преимущество будет на стороне квалификации обязательства как договорного. Полагаем, что при возникновении вопросов в квалификации - преимущественная квалификация обязательства в качестве договорного связана с легкостью его определения. Поскольку общепризнанным является первоначальный признак договорных обязательств - наличие соглашения между сторонами.

Таким образом, правовая квалификация внедоговорных трансграничных обязательств в Российской Федерации и Испании эволюционировала. В Испании квалификация изменилась в пользу автономной квалификации. В РФ квалификация данного вида обязательств по-прежнему осуществляется по lex fori. Однако наметилась тенденция, что в случае наличия тесной связи с договором, вид внедоговорных трансграничных обязательств может быть квалифицирован в качестве договорного обязательства.

${ }^{46}$ Rafael Arenas García. Указ. соч. Р. 404.

${ }^{47}$ См.: Rafael Arenas García. Указ. соч. Р. 398. (http://adipr.files.wordpress.com/2007/06/aedipr-2006-jornadasarenas-garcia.pdf). Дата посещения 05.01.13.

\section{Библиография:}

1. Абраменков М.С. Проблемы коллизионно-правового регулирования наследственных отношений в международном частном праве. Дисс. к. ю. н. М., 2007. С. 145.

2. Бирюкова Н.С. Проблема квалификации в международном частном праве. Дисс. к. ю. н. М., 2007. С. 62. C. 63. С. 80 .

3. Болонин С.Ю. Правотолкование и правовое регулирование. Дисс. к. ю. н. Казань, 2010.

4. Звеков В.П. Обязательства из причинения вреда здоровью в международном частном праве. Дис. к.ю.н. М., 1964.

5. Звеков В.П. Коллизии законов в международном частном праве. М., 2007. С. 297-326.

6. Канашевский В.А. Международное частное право. M., 2009. C. 114.

7. Коробов А.П. Правовая квалификация: основы, понятие, значение, этапы. Дисс. к. ю. н. Саратов, 2005. С. 13.

8. Международное частное право. Отв. ред. Дмитриева Г.К. - 3-е изд., перераб. и доп. М., 2010. С. 139. С. 140. C. 141, C. 142, C. 144.

9. Международное частное право. Т.1. Общая часть. Отв. ред. Лебедев С.Н., Кабатова Е.В. М., 2011. С.267.

10. Надежин Г.Н. Доктринальное толкование норм права. Дисс. к. ю. н. Нижний Новгород, 2005.

11. Новиков Н.И. Нормативное толкование в механизме правового регулирования. Дисс. к. ю. н. Ростов-наДону, 2009.

12. Толстых В.Л. Международное частное право: коллизионное регулирование. СПб, 2004. С. 173.

13. Федосеева Г.Ю. Международное частное право. М., 2007. C. 120 , C. 124.

14. Derecho internacional privado. 5a edicion. Carlos Espligues Mota, Jose Luis Iglesias Buhigues. Valencia, 2011. P. 222.

15. Rafael Arenas Garcia. La distinction entre obligaciones contractuales y obligaciones extracontractuales en los instrumentos comunitarios de derecho internacional privado. Anuario de derecho internacional privado, 2006. № 4. P. 398. P. 400. P. 403. P. 404. P. 415. P. 416.

16. Derecho internacional privado. Alfonso-Luis Calvo Carravaca, Javier Carrascosa Gonzalez. Granada, 2008. Volume 1. P. 270-271.

\section{References (transliteration):}

1. Abramenkov M.S. Problemy kollizionno-pravovogo regulirovaniya nasledstvennykh otnosheniy v mezhdunarodnom chastnom prave. Diss. k. yu. n. M., 2007. C. 145.

2. Biryukova N.S. Problema kvalifikatsii v mezhdunarodnom chastnom prave. Diss. k. yu. n. M., 2007. C. 62. C. 63. C. 80. 
Транснациональные интересы

3. Bolonin S.Yu. Pravotolkovanie i pravovoe regulirovanie. Diss. k. yu. n. Kazan', 2010.

4. Zvekov V.P. Obyazatel'stva iz prichineniya vreda zdorov'yu v mezhdunarodnom chastnom prave. Dis. k.yu.n. M., 1964.

5. Zvekov V.P. Kollizii zakonov v mezhdunarodnom chastnom prave. M., 2007. S. 297-326.

6. Kanashevskiy V.A. Mezhdunarodnoe chastnoe pravo. M., 2009. S. 114.

7. Korobov A.P. Pravovaya kvalifikatsiya: osnovy, ponyatie, znachenie, etapy. Diss. k. yu. n. Saratov, 2005. C. 13.

8. Dmitrieva G.K. Mezhdunarodnoe chastnoe pravo. Otv. red. Dmitrieva G.K. - 3-e izd., pererab. i dop. M., 2010. S. 139. S. 140. S. 141, C. 142 , C. 144.
9. Lebedev S.N., Kabatova E.V. Mezhdunarodnoe chastnoe pravo. T.1. Obshchaya chast'. Otv. red. Lebedev S.N., Kabatova E.V. M., 2011. S. 267 .

10. Nadezhin G.N. Doktrinal'noe tolkovanie norm prava. Diss. k. yu. n. Nizhniy Novgorod, 2005.

11. Novikov N.I. Normativnoe tolkovanie v mekhanizme pravovogo regulirovaniya. Diss. k. yu. n. Rostov-na-Donu, 2009.

12. Tolstykh V.L. Mezhdunarodnoe chastnoe pravo: kollizionnoe regulirovanie. SPb, 2004. S. 173.

13. Fedoseeva G.Yu. Mezhdunarodnoe chastnoe pravo. M., 2007. S. 120 , S. 124. 